\title{
Prototipe Pengendalian Kualitas Udara Indoor Menggunakan Mikrokontroler dengan Sensor MQ135, DHT-22 dan Filter HEPA
}

\author{
Gita Pati Humairoh ${ }^{1 *}$, Rama Dani Eka Putra \\ ${ }^{1)}$ Program Studi Teknik Lingkungan, Fakultas Teknik, Universitas Universal \\ ${ }^{2}$ Program Studi Teknik Industri, Fakultas Teknik, Universitas Universal \\ Komplek Maha Vihara Duta Maitreya, Bukit Beruntung, Sungai Panas, Batam, 29433 \\ *Koresponden email: gita.pati.humairoh@gmail.com
}

Diterima: 8 November 2021

Disetujui: 14 Desember 2021

\begin{abstract}
Indoor air pollution is a very serious health issue in comparison with outdoor air conditions. The current pandemic of COVID-19 causes people to remain indoors at all times. It is unimaginable that during this pandemic a smog-related disaster could occurs that could aggravate human respiratory diseases, thus requires additional air quality monitoring which can filter clean air into the room. The purpose of this study is to produce a prototype of air quality control that can provide a good air circulation system and hold the temperature and humidity in the room. This research was conducted with an Arduino Uno microcontroller and an MQ-135 gas sensor to detect $\mathrm{CO}_{2}$ gas and a DHT-22 sensor for measuring room temperature and humidity by comparing the results of using a HEPA filter. The research results of the prototype make it possible to generate the room temperature using a HEPA filter and air humidifier whose average is $27.7^{\circ} \mathrm{C}$. Another parameter that is performed is the $\mathrm{CO}_{2}$ measurement, it is found that the average $\mathrm{CO}_{2}$ in the test using a HEPA filter and an air humidifier is 496 PPM.
\end{abstract}

Keywords: $\mathrm{CO}_{2}$, indoor air, microcontroller, temperature, $\mathrm{HEPA}$

\begin{abstract}
Abstrak
Pencemaran udara dalam ruangan menjadi masalah kesehatan yang sangat serius dibandingkan dengan kondisi udara di luar ruangan. Terjadinya pandemi Covid-19 saat ini membuat masyarakat selalu berada di dalam ruangan, tidak bisa dibayangkan jika saat pandemi ini terjadi bencana kabut asap yang dapat memperburuk kondisi pernafasan manusia, sehingga butuh sebuah alternatif pengendalian kualitas udara yang dapat menyaring udara bersih masuk ruangan. Tujuan penelitian ini adalah menghasilkan prototipe pengendalian kualitas udara yang mampu memberikan sistem sirkulasi udara yang baik dan menjaga suhu serta kelembaban ruangan. Penelitian menggunakan mikrokontroler Arduino Uno dan sensor gas MQ-135 untuk mendeteksi gas $\mathrm{CO}_{2}$ dan sensor DHT-22 untuk mendeteksi suhu dan kelembaban ruangan dengan membandingkan hasil penggunaan filter HEPA. Hasil penelitian dari prototipe mendapatkan suhu ruangan yang dihasilkan menggunakan filter HEPA dan Air Humadifier memiliki rata-rata sebesar 27,7 derajat Celsius. Parameter lain yang dilakukan adalah pengukuran $\mathrm{CO} 2$ didapatkan bahwa rata-rata $\mathrm{CO} 2$ dalam pengujian menggunakan filter HEPA dan Air Humadifier sebesar 496 PPM.
\end{abstract}

Kata Kunci: CO2, Mikrokontroler, Udara Indoor, Suhu, HEPA

\section{Pendahuluan}

Kualitas udara di dalam ruangan sangat berkaitan dengan efisiensi kerja dan kesehatan manusia [1]. Dalam penelitian [2] bahwa orang menghabiskan $90 \%$ waktunya di dalam ruangan baik itu ruangan pribadi maupun di publik seperti ruang kelas. Terjadinya pandemi dengan skala besar di seluruh dunia tahun ini, menyebabkan banyak penduduk diisolasi dalam ruangan dengan kurun waktu yang lama, sehingga sangat penting untuk meningkatkan kualitas udara dalam ruangan [2][3]. Polusi udara dalam ruangan mengacu pada akumulasi dan difusi berbagai polutan fisik, bahan kimia, dan biologi yang dapat mengakibatkan penurunan kualitas udara dalam ruangan serta dapat mengganggu kesehatan manusia yang bisa memberikan risiko terhadap aktivitas kehidupan sehari-hari [2]. Suhu dan kelembaban ruangan sangat mempengaruhi efektivitas kegiatan dalam melakukan pekerjaan.

Bekerja pada lingkungan yang terlalu lembab atau terlalu panas, dapat menurunkan kemampuan fisik tubuh dan menyebabkan kelelahan sedangkan pada lingkungan yang terlalu dingin, dapat menyebabkan hilangnya fleksibilitas motorik tubuh [4]. Kesegaran udara yang dihirup dapat berdampak negatif pada manusia jika udara tersebut mengandung karbondioksida (CO2) yang berlebihan. $\mathrm{CO} 2$ menjadi polusi udara jika kadar $\mathrm{CO} 2$ berlebihan dalam udara, yaitu lebih dari 5000 ppm, sehingga dapat mengakibatkan 
gangguan kesehatan [5]. Oleh karena itu diperlukan alat pendeteksi kualitas udara di dalam ruangan agar kita dapat mengetahui kadar karbondioksida $(\mathrm{CO} 2)$, suhu dan kelembaban. Saat ini terdapat berbagai instrumen pengukuran kualitas udara salah satunya dengan menggunakan mikrokontroler dan penggunaan sensor.

Mikrokontroler yang digunakan dalam penelitian ini adalah jenis Arduino UNO. Arduino merupakan papan mikrokontroler yang menggunakan prosesor Atmel AVR memiliki sifat open source dan dirancang untuk memudahkan pengguna dalam mengembangkan berbagai proyek [6]. Sedangkan untuk sensor gas CO2 dan sensor suhu kelembaban adalah sensor MQ-135 dan sensor DHT-22. Sensor gas MQ135 adalah sensor gas yang bisa mendeteksi gas seperti amonia NH3, NOx, alkohol, CO2 dan sebagainya. Sensor ini memiliki tingkat sensitivitasnya tinggi dan respon yang cepat, dengan hasil pengukurannya sensor ini memiliki satuan ppm. Sensor gas MQ-135 bekerja dengan cara gas yang diterima dan mengubah nilai resistansi bila terkena gas. Sensor ini juga memiliki daya tahan yang baik untuk penggunaan penanda bahaya polusi karena praktis dan memiliki tegangan 5V [7].

Sensor DHT- 22 ini merupakan sensor yang digunakan untuk mendeteksi suhu dan kelembaban udara. Pada sensor ini daya yang digunakan sebesar 3.3V-6V. Sensor ini dapat mengukur suhu dengan rentang nilai - 40oC sampai $80 \mathrm{oC}$, dan bisa mengukur kelembaban dengan rentang nilai $0 \%$ sampai $100 \%$ [8]. Filter HEPA dapat mengurai partikel udara yang masuk pada seratnya sehingga tujuan dari penelitian ini adalah untuk mengetahui perbandingan hasil pengukuran kualitas udara menggunakan prototipe pengendali kualitas udara menggunakan sensor MQ135 dan DHT22.

\section{Metode Penelitian \\ Pembuatan Sistem}

Perancangan komponen berdasarkan perlengkapan yang dibutuhkan dalam sebuah sistem agar perangkat dapat digunakan sesuai dengan fungsi yang telah diperuntukkan [10]. Tahapan pertama yaitu merancang blok diagram rangkaian sistem yang dapat dilihat pada Gambar 1. Blok diagram merupakan gambaran dasar sebelum melakukan perancangan perangkat, sedangkan perancangan sistem terdiri dari perancangan hardware dan software. Perancangan Hardware diperuntukkan untuk membuat konfigurasi pin input output komponen hardware terlebih dahulu kemudian dilanjutkan dengan membuat model perangkat stasiun pengukuran dan pemantauan tingkat pencemaran udara. Sedangkan perancangan software diperuntukkan mikrokontroler dan database dari penelitian.

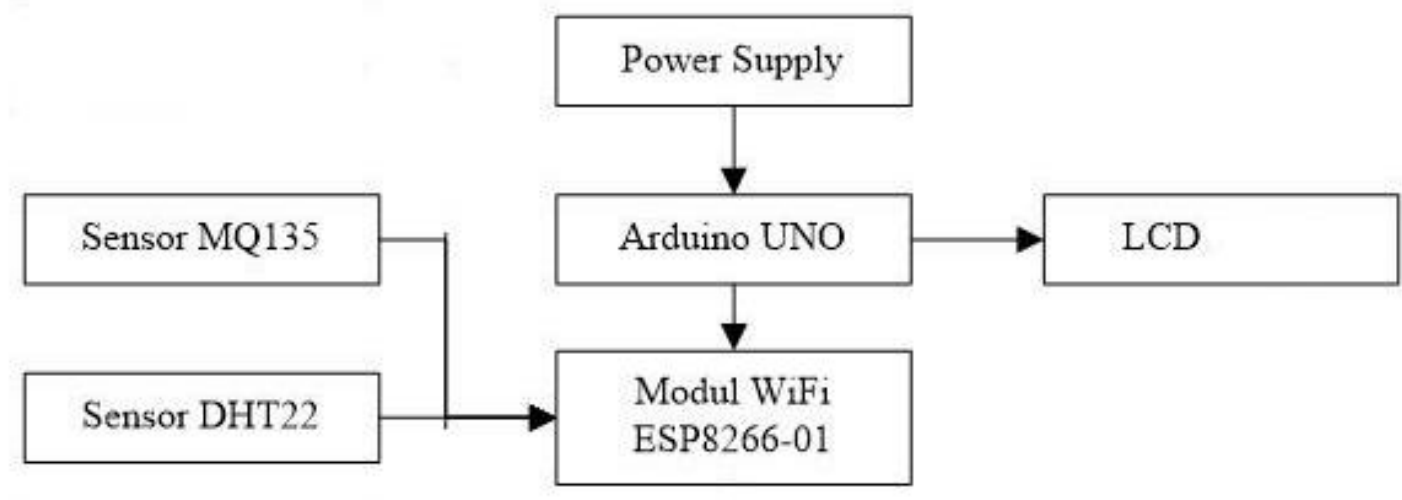

Gambar 1. Blok diagram rangkaian sistem keseluruhan Sumber: Data penelitian (2021)

\section{Pembuatan Prototipe}

Miniatur ruangan ini dibuat dengan menggunakan bahan akrilik dengan ukuran panjang $80 \mathrm{~cm}$, lebar $60 \mathrm{~cm}$ dan tinggi $30 \mathrm{~cm}$ yang akan direkatkan dengan lem. Ukuran ini dibuat berdasarkan ruangan kelas dalam pembelajaran sekolah. Kendali yang berukuran panjang $8 \mathrm{~m}$, lebar $6 \mathrm{~m}$, dan tinggi $3 \mathrm{~m}$ sehingga mendapatkan rasio pembandingan sebesar 1:10. Pada miniatur ruangan ini juga terdapat sebuah pintu dan dua buah jendela, bagian atas dari miniatur ini dirancang agar bisa buka tutup yang bertujuan untuk memudahkan dalam memasukkan sistem perangkat keras ke dalamnya. Kemudian, dirangkai kipas 12 volt pada 4 sudut ruangan dengan 2 kipas dipasang Filter HEPA untuk menyaring udara terbaik dari luar. Mikrokontroler yang digunakan adalah Arduino Uno. Penelitian menggunakan 2 buah sensor sebagai input 
yaitu MQ-135 dan DHT-22. Sensor MQ-135 digunakan untuk mendeteksi gas dan sensor DHT-22 digunakan untuk mendeteksi suhu dan kelembaban udara.

Output dari sistem ini berupa actuator yaitu 4 buah kipas dan sebuah air humidifier. Dua buah kipas digunakan untuk memasukkan udara ke dalam ruangan serta mendinginkan ruangan jika udara didalam ruangan panas, sedangkan 2 buah kipas lainnya digunakan untuk membuang gas berbahaya jika terdeteksi oleh sensor MQ-135. Air humidifier berfungsi untuk melembabkan udara yang kering. Kipas dan air humidifier ini bekerja sesuai dengan parameter yang dibaca oleh kedua sensor. Sistem komunikasi yang digunakan pada sistem pembersih udara ini adalah modul Wi-Fi ESP 8266. Sumber tegangan yang digunakan untuk ESP 8266 adalah 3.3V yang langsung diambil dari Arduino. RX ESP 8266 dihubungkan dengan TX Arduino, dan TX ESP 8266 dihubungkan dengan RX Arduino.

\section{Running Penelitian}

Running bertujuan untuk membuktikan bahwa sub sistem dapat teruji sebelum dirangkai menjadi suatu sistem utuh dan dapat beroperasi sesuai dengan fungsi yang telah ditetapkan. Pengujian sistem secara keseluruhan dilakukan untuk mengetahui apakah sistem dapat mengukur dan memantau tingkat pencemaran udara dan dapat ditelusuri untuk melihat hasil pengukuran dan pemantauan tingkat pencemaran udara [13].

\section{Analisa Data}

Analis data dilakukan setelah mendapatkan hasil pengujian. Analisis data dilakukan dengan membandingkan hasil tiap parameter pengujian untuk semua variabel yang diteliti seperti sensor gas MQ135 untuk mendeteksi gas CO2, sensor DHT-22 untuk mendeteksi suhu dan kelembaban ruangan.

\section{Hasil dan Pembahasan}

\section{Prototipe Pengendali Udara Indoor}

Prototipe pengendali udara indoor pada penelitian ini dibuat menjadi dua tipe, yaitu menggunakan penyaring udara HEPA dan tanpa HEPA yang dipasangkan pada kipas udara pada tiap sisi prototipe. Kipas pada prototipe ini terdapat 1 pasang untuk udara masuk dan 1 pasang udara keluar untuk mengoptimalkan sirkulasi udara pada sisi depan dan belakang. HEPA dipasang pada tiap sisi kipas setelah dilakukan running pada prototipe tanpa HEPA. Adapun prototipe pengendali udara indoor dapat dilihat pada Gambar 2.

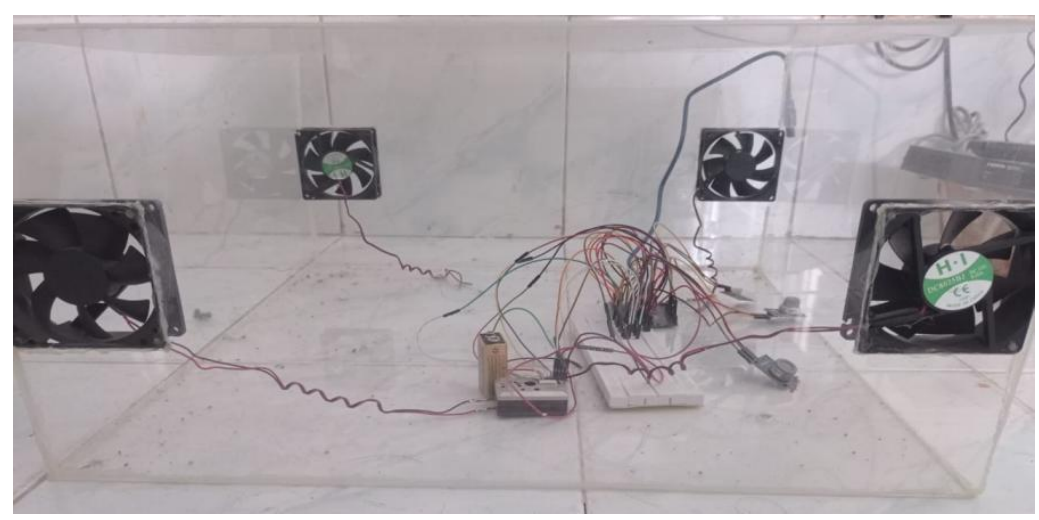

Gambar 2. Prototipe pengendali udara indoor Sumber: Data penelitian (2021)

\section{Rekapitulasi Running Prototipe}

Running Prototipe pada penelitian ini dibagi atas 2 tahapan. Tahapan pertama dilakukan pengujian pengendalian kualitas udara dengan dan tanpa filter HEPA dengan tidak adanya dukungan Air Humidifier sebagai pelembab ruangan. Tahapan selanjutnya adalah pengujian pengendalian kualitas udara dengan dan tanpa filter HEPA dengan adanya penambahan Air Humidifier. Adapun hasil rekapitulasi pada masingmasing tahapan dapat dilihat pada Tabel 1 dan Tabel 2. 
Tabel 1. Rekapitulasi pengukuran kualitas udara tidak menggunakan air humidifier

\begin{tabular}{|c|c|c|c|c|c|c|c|}
\hline \multicolumn{8}{|c|}{ Pengukuran Tidak Menggunakan Air Humidifier } \\
\hline No. & $\begin{array}{c}\text { Detik } \\
\text { (Second) }\end{array}$ & $\begin{array}{c}\text { DHT22 tidak } \\
\text { menggunakan } \\
\text { HEPA (Celcius) }\end{array}$ & $\begin{array}{c}\text { DHT22 } \\
\text { dengan HEPA } \\
\text { (Celcius) }\end{array}$ & $\begin{array}{l}\text { Selisih } \\
\text { Nilai }\end{array}$ & $\begin{array}{l}\text { MQ135 Tidak } \\
\text { menggunakan } \\
\text { HEPA (PPM) }\end{array}$ & $\begin{array}{l}\text { MQ135 } \\
\text { dengan } \\
\text { HEPA } \\
\text { (PPM) }\end{array}$ & $\begin{array}{l}\text { Selisih } \\
\text { Nilai }\end{array}$ \\
\hline 1. & 0 & 26,2 & 31,1 & 4,9 & 700 & 520 & -180 \\
\hline 2. & 20 & 27,1 & 31,1 & $-4,3$ & 701 & 521 & -182 \\
\hline 3. & 40 & 29,9 & 34,4 & $-4,8$ & 702 & 522 & -182 \\
\hline 4. & 60 & 35,4 & 34,4 & $-5,2$ & 703 & 523 & -182 \\
\hline 5. & 80 & 39,2 & 37,2 & $-2,4$ & 704 & 524 & -182 \\
\hline 6. & 100 & 39,6 & 37,2 & $-3,6$ & 705 & 525 & -182 \\
\hline 7. & 120 & 39,6 & 39,2 & $-1,7$ & 706 & 526 & -182 \\
\hline 8. & 140 & 40,8 & 39,2 & $-1,6$ & 707 & 527 & -180 \\
\hline 9. & 160 & 40,9 & 41,1 & 0,2 & 708 & 528 & -180 \\
\hline 10. & 180 & 41,7 & 45,2 & 3,5 & 709 & 529 & -180 \\
\hline 11. & 200 & 43,1 & 45,2 & 2,1 & 710 & 530 & -180 \\
\hline 12. & 220 & 43,1 & 45,2 & 2,1 & 711 & 531 & -180 \\
\hline 13. & 240 & 43,1 & 45,2 & 2,1 & 712 & 532 & -180 \\
\hline
\end{tabular}

Sumber: Data penelitian (2021)

Berdasarkan hasil pengukuran pada Tabel 1 didapatkan rata-rata suhu tidak menggunakan HEPA sebesar $37^{\circ}$ Celsius dan stabil pada waktu pengujian 3 menit pertama, sedangkan rata-rata suhu menggunakan HEPA $38,9^{\circ} \mathrm{C}$. Hal ini dikarenakan udara yang masuk lebih sedikit dikarenakan adanya filter yang menyaring udara terlebih dahulu. CO2 didapatkan rata-rata tidak menggunakan HEPA sebesar 706 PPM dan stabil pada waktu pengujian 3 menit pertama, sedangkan rata-rata CO2 menggunakan HEPA 526 PPM. Berdasarkan hasil pengukuran antara menggunakan filter HEPA dan tidak pada parameter $\mathrm{CO} 2$ terdapat menurunkan kadar $\mathrm{CO}_{2}$ hal ini dikarenakan filter HEPA dapat menyaring $\mathrm{CO}_{2}$ dengan baik.

Tabel 2. Rekapitulasi pengukuran kualitas udara tidak menggunakan air humidifier

\begin{tabular}{|c|c|c|c|c|c|c|c|}
\hline \multicolumn{8}{|c|}{ Pengukuran Menggunakan Air Humidifier } \\
\hline No. & $\begin{array}{c}\text { Detik } \\
\text { (Second) }\end{array}$ & $\begin{array}{c}\text { DHT22 tidak } \\
\text { menggunakan } \\
\text { HEPA (Celcius) }\end{array}$ & $\begin{array}{l}\text { DHT22 dengan } \\
\text { HEPA (Celcius) }\end{array}$ & $\begin{array}{l}\text { Selisih } \\
\text { Nilai }\end{array}$ & $\begin{array}{l}\text { MQ135 Tidak } \\
\text { menggunakan } \\
\text { HEPA (PPM) }\end{array}$ & $\begin{array}{c}\text { MQ135 } \\
\text { dengan HEPA } \\
\text { (PPM) }\end{array}$ & $\begin{array}{l}\text { Selisih } \\
\text { Nilai }\end{array}$ \\
\hline 1. & 0 & 25,2 & 26,5 & 1,3 & 600 & 490 & -110 \\
\hline 2. & 20 & 25,2 & 26,5 & $-0,9$ & 601 & 491 & -112 \\
\hline 3. & 40 & 25,2 & 26,5 & $-0,6$ & 602 & 492 & -112 \\
\hline 4. & 60 & 25,2 & 26,5 & 0,2 & 603 & 493 & -112 \\
\hline 5. & 80 & 27,1 & 27,5 & 1 & 604 & 494 & -112 \\
\hline 6. & 100 & 27,1 & 27,5 & 2 & 605 & 495 & -112 \\
\hline
\end{tabular}




\begin{tabular}{cccccccc}
\hline 7. & 120 & 27,1 & 27,5 & 2,1 & 606 & 496 & -112 \\
8. & 140 & 27,1 & 27,5 & 3,6 & 607 & 497 & -110 \\
9. & 160 & 27,1 & 27,5 & 4,2 & 608 & 498 & -110 \\
10. & 180 & 27,7 & 28,5 & 4,2 & 609 & 499 & -110 \\
11. & 200 & 28,1 & 29,5 & 4,2 & 610 & 500 & -110 \\
12. & 220 & 28,4 & 29,5 & 4,1 & 611 & 501 & -110 \\
13. & 240 & 28,4 & 29,5 & 4,2 & 612 & 502 & -110 \\
\hline
\end{tabular}

Sumber: Data penelitian (2021)

Berdasarkan hasil pengukuran pada Tabel 2 didapatkan rata-rata suhu tidak menggunakan HEPA sebesar 26,8 $8^{\circ}$ Celsius dan stabil pada waktu pengujian 3 menit pertama, sedangkan rata-rata suhu menggunakan HEPA 27,7 Celcius. Pada Tabel 2 juga dapat dilihat terjadi penurunan suhu antara menggunakan dan tidak menggunakan filter HEPA dengan adanya penambahan Air Humidifier. CO2 tidak menggunakan HEPA rata-rata sebesar 606 PPM dan stabil pada waktu pengujian 3 menit pertama, sedangkan rata-rata $\mathrm{CO} 2$ menggunakan HEPA 496 PPM. Berdasarkan hasil pengukuran antara menggunakan dan tidak menggunakan filter HEPA pada parameter $\mathrm{CO} 2$ dapat menurunkan kadar $\mathrm{CO} 2$ hal ini dikarenakan filter HEPA dapat menyaring $\mathrm{CO} 2$ dengan baik dan hal ini menjadi lebih baik setelah ditambahkannya Air Humidifier.

\section{Analisa Hasil Running}

Berdasarkan Tabel 1 dan Tabel 2 terdapat perbedaan signifikan antara pengujian dengan adanya penambahan Air Humidifier dan tidak menggunakan Air Humidifier. Berdasarkan Tabel 1 dan Tabel 2 selisih nilai pada sensor DHT 22 dan MQ135 terdapat penurunan nilai PPM yang berada pada Nilai Ambang Batas yang telah di tentukan.

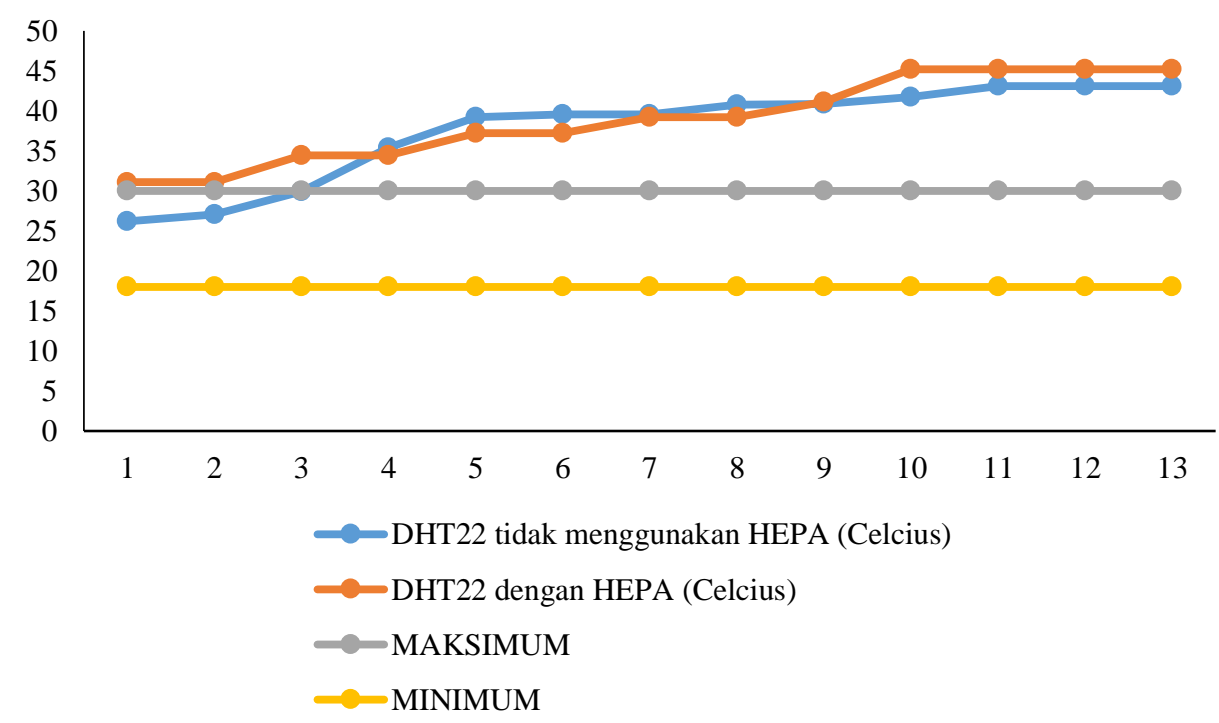

Gambar 2. Grafik pengukuran suhu tidak menggunakan air humidifier

Berdasarkan Gambar 2, diketahui bahwa grafik pengukuran suhu tidak menggunakan Air Humidifier melewati dari Nilai Ambang Batas suhu dalam ruangan. Kurangnya suhu pada ruangan dapat menurunkan konsentrasi pada individu yang berada pada ruangan tersebut, bahwa suhu yang terlalu panas akan menyebabkan manusia kekurangan konsentrasi [9]. 


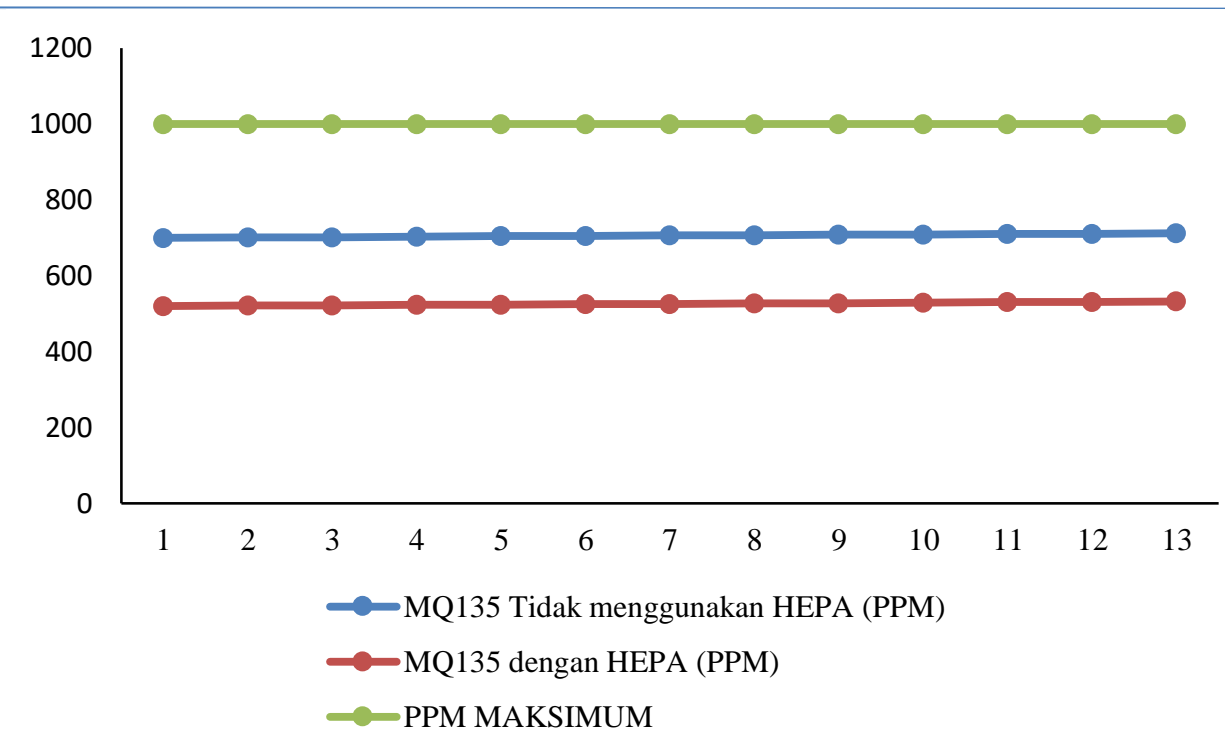

Gambar 3. Grafik pengukuran $\mathrm{CO} 2$ tidak menggunakan air humidifier

Berdasarkan Gambar 3, diketahui bahwa grafik pengukuran CO2 tidak menggunakan Air Humidifier berada dalam Nilai Ambang Batas CO2 dalam ruangan yaitu antara 0 sampai dengan 1000 PPM. Hal ini tidak berdampak pada kenyamanan individu bila berada pada ruangan tertutup[11]. Sedangkan bila melebihi dari ambang batas yang diperbolehkan akan berdampak pada kesehatan manusia[15].

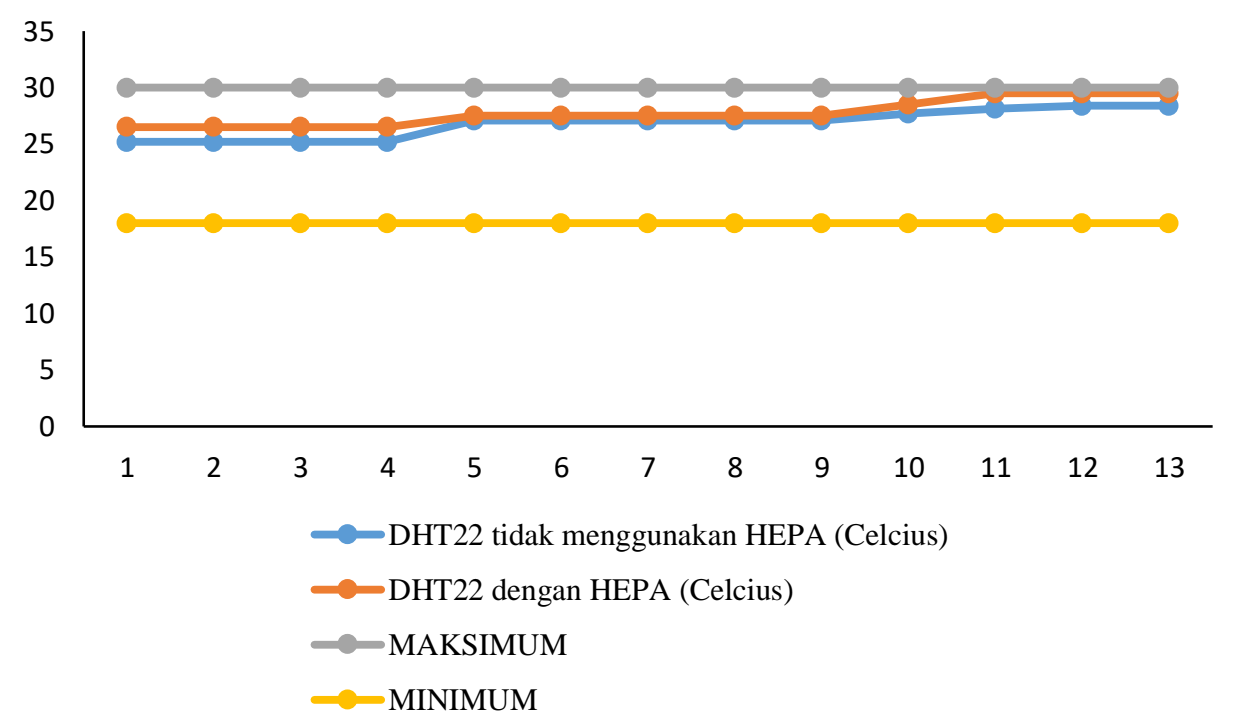

Gambar 4. Grafik pengukuran suhu menggunakan air humidifier

Berdasarkan Gambar 4, diketahui bahwa grafik pengukuran suhu menggunakan Air Humidifier berada dalam Nilai Ambang Batas suhu dalam ruangan yaitu antara 18 sampai dengan 30 derajat Celcius. Penambahan Air Humidifier lebih baik ketimbang dibandingkan dengan tidak menggunakan Air Humidifier untuk kelembaban ruangan dan menjaga suhu yang tersedia. 


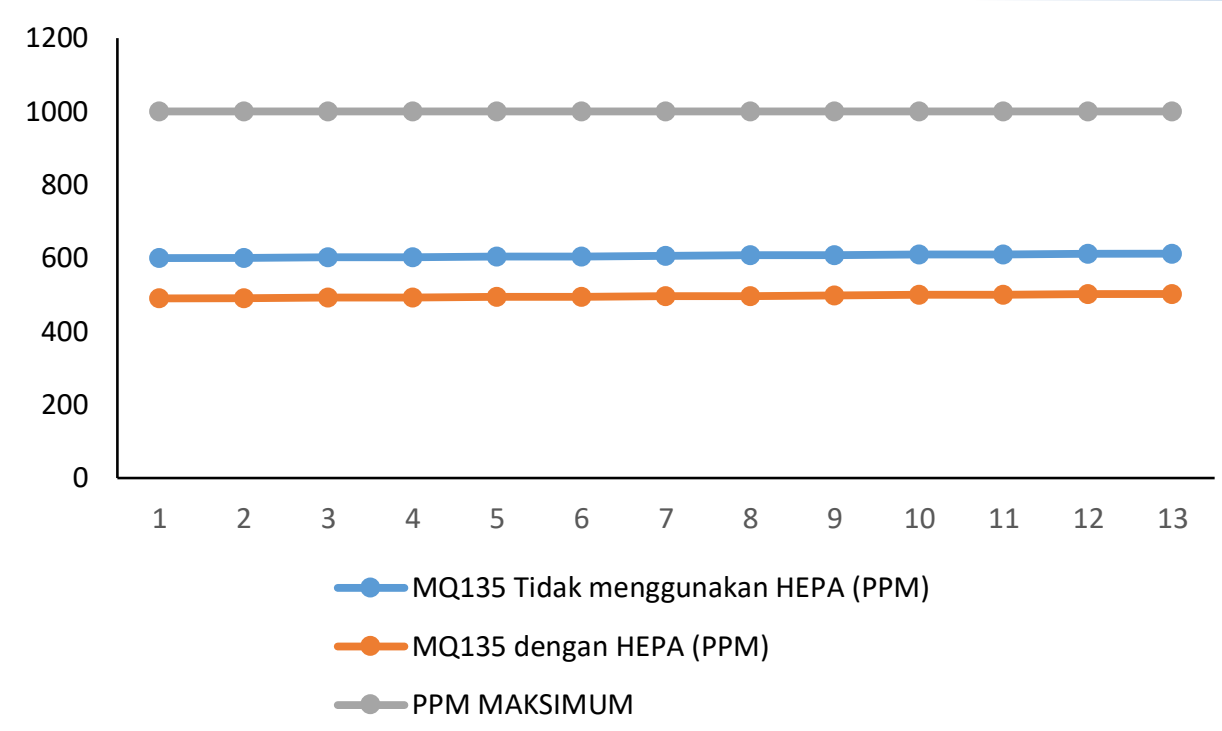

Gambar 5. Grafik pengukuran CO2 menggunakan air humidifier

Berdasarkan Gambar 5, diketahui bahwa grafik pengukuran suhu menggunakan Air Humidifier berada dalam Nilai Ambang Batas suhu dalam ruangan dan mendapatkan hasil yang lebih ketika menggunakan filter HEPA yang berada pada rentang 490 sampai dengan 500 PPM dan ini merupakan nilai ambang batas yang diizinkan ASHARE untuk kesehatan yang berada di bawah 1000 PPM[12]. hal ini dikarenakan adanya filter atau sirkulasi yang dapat mengeluarkan dan menyerap CO2 secara baik [14].

\section{Kesimpulan}

Setelah dilakukan perancangan dan pengujian terhadap komponen yang digunakan, dapat disimpulkan bahwa prototipe pengendalian udara menggunakan sensor DHT22 dan MQ135 dengan menambahkan filter HEPA dan Air Humidifier memiliki perbedaan signifikan pada hasil penelitian. Suhu ruangan yang dihasilkan menggunakan filter HEPA dan Air Humidifier memiliki rata-rata sebesar 27,7 derajat Celcius. Parameter lain yang dilakukan adalah pengukuran $\mathrm{CO} 2$ didapatkan bahwa rata-rata $\mathrm{CO} 2$ dalam pengujian menggunakan filter HEPA dan Air Humidifier didapatkan rata-rata sebesar 496 PPM.

\section{Ucapan Terima Kasih}

Ucapan terimakasih ditujukan kepada Universitas Universal khususnya yang telah mendukung diberbagai aspek untuk melakukan penelitian ini dan terima kasih juga disampaikan kepada Deputi Bidang Penguatan Riset dan Pengembangan Kementerian Riset dan Teknologi/ Badan Riset dan Inovasi Nasional untuk menyediakan dana penelitian. Naskah ini adalah bagian dari dana penelitian dosen pemula dibawah kontrak: 077/LL10/PG-PDTT/2021.

\section{Referensi}

[1] Chen, H., Du, R., Ren, W., Zhang, S., Du, P. and Zhang, Y. (2020). The Microbial Activity in PM2.5 in Indoor Air: As an Index of Air Quality Level. Aerosol Air Qual. Res. https://doi.org/10.4209/aaqr. 2020.03.0101

[2] Cincinelli, A. and Martellini, T. (2017). Indoor Air Quality and Health. Int. J. Env. Res. Public Health.14 (11): 5

[3] Lakey, P.S.J., Wisthaler, A., Berkemeier, T., Mikoviny, T., Poeschl, U. and Shiraiwa, M. (2017). Chemical kinetics of multiphase reactions between ozone and human skin lipids:Implications 480 for indoor air quality and health effects. Indoor Air.

[4] H. Nainggolan, M. Yusfi. (2013). Rancang Bangun Sistem Kendali Temperatur dan Kelembaban Relatif pada Ruangan dengan Menggunakan Motor DC Berbasis Mikrokontroler ATmega8535, Jurnal Fisika Unand.

[5] Rahmi, D, A. Sumardi. Setiawan I. (2019). Monitoring Kandungan Karbondiokasida (CO2) dalam sebuah model ruangan berbasis mikrokontroler ATMEGA8535.

[6] K. Abdul, (2015). From Zero to A Pro Arduino. Yogyakarta: Andi OFFSET.

[7] R. Tem, (2018). "Datasheets MQ-135 Sensor". 
[8] A. H. Saptadi, (2016). "Perbandingan Akurasi Pengukuran Suhu dan Kelembaban Antara Sensor DHT11 dan DHT22," J. INFOTEL - Inform. Telekomun. Elektron., vol. 6, no. 2.

[9] A.Sarinda., Sudarti., Subiki. (2017). "Analisa Perubahan Suhu Ruangan Terhadap Kenyamanan Termal di Gedung 3 FKIP Universitas Jember”. Jurnal Pembelajaran Fisika. Vol.6, no.3.

[10] Ramady, G, D., Mahardika, A, G., Lestari, N, S., Syafruddin, Abadi, S, C., Sukandi, G, K. (2020). Perancangan Model Simulasi Sistem Pengendalian Suhu Ruang Kelas Berbasis Internet of Things. Prosiding Seminar Nasional Riset Teknologi Terapan.

[11] Widodo, S., Amin, M,M., Sutrisman, A, Putra, A,A. (2017). Rancang Bangun Alat Monitoring Kadar Udara Bersih dan Gas Berbahaya $\mathrm{CO}, \mathrm{CO} 2$, dan $\mathrm{CH} 4$ di dalam Ruangan Berbasis Mikrokontroler. Jurnal Pseudocode, Vol IV, No.2.

[12] Talarosha, B. (2017). Konsentrasi CO2 pada Ruang Kelas dengan Sistem Ventilasi Alami sebuah Penelitian Awal. Jurnal Lingkungan Binaan Indonesia.

[13] Kurniawan, A., Munadi, R., Mayasari, R. (2016). Implementasi dan Analisa Jaringan Wireless Sensor untuk Monitoring Suhu, Kelembaban, dan Kadar CO2 pada Ruangan.

[14] Andrizal, Yani, P, I., Antonisfia, A. (2020). Monitoing dan Kontrol Kadar CO2 dalam Ruangan Berbasis Sistem Penciuman Elektronik. Seminar Nasional Terapan Riset Inovatif (Sentrinov). Vol.6, No.1

[15] Nebath, E., Pang, D., Wuwung, J, O. (2014). Rancang Bangun Alat Pengukur Gas Berbahaya CO dan CO2 di Lingkungan Industri. E-Journal Teknik Electro dan Komputer. 